\title{
Peter C. Gerszten and Samul Ryu (eds.): Spine radiosurgery
}

\section{2nd Edition, Thieme Verlag New York, Stuttgart, Delhi, Rio de Janeiro, 2015, 250 pp, 150 III, Hardcover, EUR (D) 159,99 EUR (A) 164,50 CHF 184,00, ISBN: 978-1-62623-034-7}

\section{Pierre Kehr ${ }^{1}$}

Received: 31 October 2017 / Accepted: 17 November 2017 / Published online: 28 November 2017

(c) Springer-Verlag France SAS, part of Springer Nature 2017

This work written by a group of specialists mainly North American in this new discipline, modern, innovating present the possibilities of them to us. The book begins with several chapters dedicated to radiobiology with in particular the study from the tolerance from the spinal cord in the animal. The following chapters are devoted to the techniques used, specific to the spine.

Several chapters are then dedicated to the treatments of the metastasis of the spine: imagery, case of metastases repeating, quality of life after radiosurgery, techniques of mini-invasive, vertebroplasties with cement percutaneous, and choice of the patients.
The fourth section of the book deals with in several chapters the malignant and benign primitive tumors of the rachis: medullary chordoma, tumors, and arteriovenous malformations.

Essential work for the modern treatment of the primitive tumors and metastases of the spine.

\section{Compliance with ethical standards}

Conflict of interest The author declares that he has no competing interests.

Pierre Kehr

pierre.kehr@gmail.com

1 Strasbourg, France 